\title{
Mut zur Individualität
}

Auch vor der Keramik- und Feuerfestbranche machen die Herausforderungen der aktuellen Zeit keinen Halt: Feuerfestauskleidungen in Öfen sollen die Energiebilanz verbessern, ihre Bestandteile sollen möglichst nachhaltig sein, Prozessdaten sollen digital verfügbar sein und automatisch ausgewertet werden, während die Prozesse selbst möglichst automatisiert ablaufen sollten. All diese Forderungen sind dabei im Angesicht steigender Energiepreise und globaler Konkurrenz zu erfüllen. Das ist keine leichte Aufgabe, und so ist die Überschrift auf der Titelseite sicherlich auch zweideutig zu verstehen: Es braucht neue Ideen, neue Konzepte und neue Materialien, und zwar in einer für die Branche knapp bemessenen Zeit.

Ein Gastkommentar in dieser Ausgabe zeigt Vorschläge auf, wie die Ziegelindustrie den Herausforderungen des Klimaschutzplans der EU bis zum Jahr 2050 begegnen kann.
Dabei geht es schnell um die Grundsatzfrage: Hat die Ziegelbranche eine Zukunft in Europa? Hier ist es an der Zeit, kreative und individuelle Lösungen zu finden, um deren Wettbewerbsfähigkeit zu sichern.

Dies lässt sich auch auf den keramischen Produktionszyklus übertragen, wo heute noch Prozesswärme ungenutzt bleibt, die auch zurückgewonnen und zur Energieeinsparung genutzt werden könnte. Mikroturbinen, die eigentlich für die Energieversorgung von Wohnhäusern vorgesehen sind, können hier den thermischen Verbrauch einzelner Anlagen decken, wobei sie sich mit aus Kompost gewonnenem Biomethan betreiben lassen. Zusammen mit einer neuen Ausmauerung des Brennofens, eigens entwickelter Beschichtung sowie dem Einsatz eines Wärmerohrtauschers und eines überarbeiteten Softwareprotokolls ergibt sich ein durchdachtes Konzept zur Energieeinsparung. Das zeigt: Es geht auch anders.

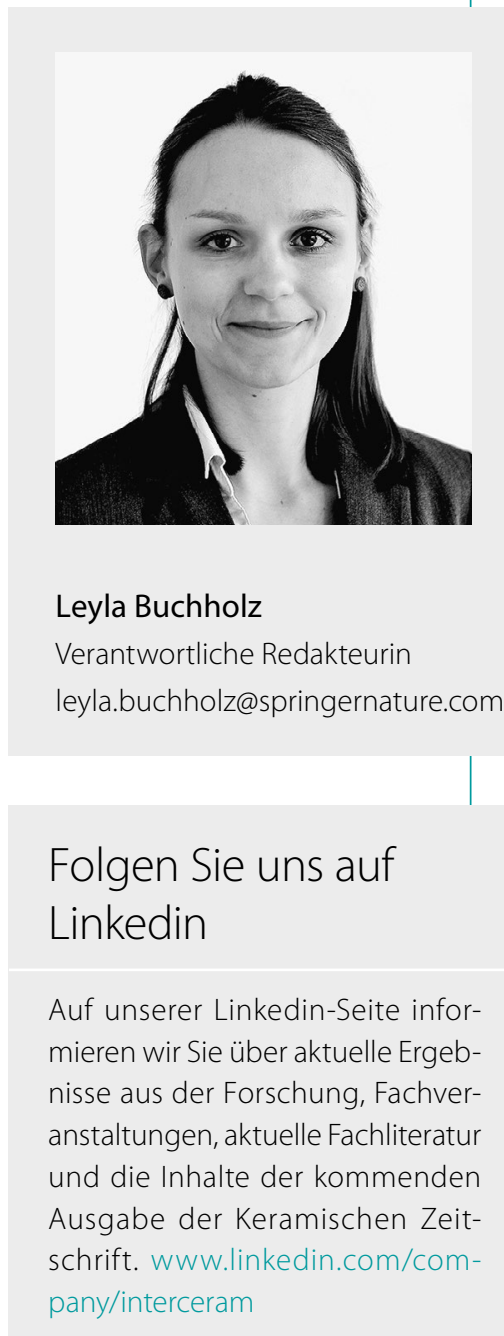

